\title{
Panel Session toward Improved Communication and Engagement with the Public after the Fukushima Daiichi Nuclear Power Plant Accident: Study Reports and Discussion with Specialists from Relevant Fields
}

\author{
Hiroko Yoshida', Yujiro Kurodaa ${ }^{2,3}$, Takahiko Kono ${ }^{4}$, Wataru Naito ${ }^{5}$, Akihiro Sakoda ${ }^{6}$ \\ ${ }^{1}$ Radioisotope Research and Education Center, Graduate School of Pharmaceutical Sciences, Tohoku University, Sendai, Japan; ${ }^{2}$ Center for Integrated Science \\ and Humanities, Fukushima Medical University, Fukushima Japan; ${ }^{3}$ Department of Prevention and Care Science, National Center for Geriatrics and \\ Gerontology, Obu, Japan; ${ }^{4}$ Sector of Fukushima Research and Development, Japan Atomic Energy Agency, Fukushima, Japan; ${ }^{5}$ Research Institute of Science \\ for Safety and Sustainability, National Institute of Advanced Industrial Science and Technology, Tsukuba, Japan; ${ }^{6}$ Ningyo-toge Environmental Engineering \\ Center, Japan Atomic Energy Agency, Okayama, Japan
}

Background: From 2018 to 2020, the Expert Study on Public Understanding after the Fukushima Daiichi Nuclear Power Plant Accident (the Expert Study Group) identified and analyzed activities designed to promote public understanding of science and radiation since the Fukushima accident, and held discussions on how to achieve public understanding in the situation where public confidence has been lost, and how experts should prepare for dealing with the public. This panel session was held at the $53^{\text {rd }}$ meeting of the Japan Health Physics Society on

Note

Received December 19, 2020

Revision March 5, 2021

Accepted March 23, 2021

Corresponding author:Yujiro Kuroda

Research Department, Fukushima Prefectural Centre for Environmental Creation, 10-2 Fukasaku, Miharu-machi, Tamura-gun, Fukushima 963-7700, Japan E-mail:kuroday@fmu.ac.jp

(iD https://orcid.org/0000-0003-0587-5423

This paper is an invited paper recommended by the Japan Health Physics Society (JHPS).

This is an open-access article distributed under the terms of the Creative Commons Attribution License (http://creativecommons.org/licenses/by-nc/4.0), which permits unrestricted use, distribution, and reproduction in any medium, provided the original work is properly cited.

Copyright $\odot 2021$ The Korean Association for Radiation Protection

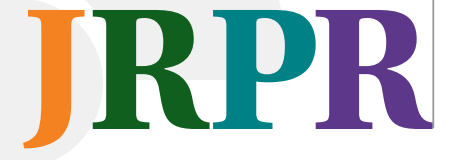
June 30, 2020.

Materials and Methods: First, three subgroup (SG) leaders reported their research methods and results. Then, two designated speakers, who participated as observers of the Expert Study Group, commented on the activities. Next, the five speakers held a panel discussion. Finally, the rapporteur summarized.

Results and Discussion: SG leaders presented reports from researchers and practitioners in health physics and environmental risks who provided information after the Fukushima accident. During the discussion, experts in sociology and ethics discussed the issues, focusing on the overall goals of the three groups, local (personal) and mass communication, and ethical values. Many of the activities instituted by the experts after the accident were aimed at public understanding of science (that is, to provide knowledge to residents), but by taking into account interactions with residents and their ethical norms, the experts shifted to supporting the residents' decision-making through public engagement. The need to consider both content and channels is well known in the field of health communication, and overlaps with the above discussion.

Conclusion: How to implement and promote the public engagement in society was discussed in both the floor and designated discussions. Cooperation between local communities and organizations that have already gained trust is also necessary in order to develop relationships with local residents in normal times, to establish an information transmission system, and to make it work effectively.

Keywords: Public Understanding, Public Engagement, Risk Communication, Stakeholder Engagement 


\section{Introduction}

Since the accident at the Tokyo Electric Power Company's Fukushima Daiichi Nuclear Power Plant (hereafter, the Fukushima accident), 10 years have already passed by March 2021. During this time, various efforts have been made to promote public understanding of radiation risks for people with little scientific expertise [1-3]. In the emergency situation immediately after the accident, so-called "crisis communication" took place, with a focus on how quickly government and experts could provide appropriate information to people $[4,5]$. During the recovery and reconstruction phase, in addition to one-way risk communication, activities to deepen public understanding through two-way risk communication were introduced $[1,6]$. In particular, activities were carried out to listen to people's values and concerns and respond to them $[7,8]$. In some cases, these activities helped to promote clear understanding among residents [9, 10]. However, such activities were often held in small groups, and there are few systematic studies and no summaries yet.

The Japan Health Physics Society (JHPS) organized an expert study group from 2018 to 2020 . JHPS's Task Group on Public Understanding after the Fukushima Daiichi Nuclear Power Plant Accident (hereafter, the Expert Study Group) identified and analyzed the activities designed to promote public understanding since the accident, and discussed how to achieve public understanding of science in the situation where public confidence has been lost, and how experts should prepare for dealing with the public.

The purpose of this paper is twofold. One is to report the discussions of the expert workshop held at the JHPS, and the other is to qualitatively analyze the opinions of other experts who participated in this session. Consequently, we will explore the attitudes of Japanese radiation protection experts toward public understanding and propose a direction for future activities.

\section{Materials and Methods}

\section{JHPS Expert Study Group}

The JHPS Expert Study Group held four meetings during the 2 years from fiscal year (FY) 2018 to FY 2019 with the participation of 13 JHPS members and six external observers. In addition to radiation protection experts, the committee members included social scientists and public health nurses living in Fukushima. Observers included citizens living in
Fukushima, enabling discussions from both experts and residents. The JHPS Expert Study Group worked on three subgroup (SG) related to public understanding. The role of SG1 is to analyze data provided to residents by experts and government after the Fukushima accident, and develop the evaluation methods. The role of SG2 is to provide "examples of practical activities to enhance public understanding of radiation risk during recovery after the accident." The role of SG3 is to discuss "how the activities of related academic societies changed before and after the accident."

\section{Panel Session at JHPS}

A panel session was held at the $53^{\text {rd }}$ Annual Meeting of the JHPS on June 30, 2020, to report on the results of the Expert Study Group and to obtain the opinions of experts outside the committee. First, the three subgroup leaders reported their research methods and results. Then, two designated speakers-Yasumasa Igarashi (University of Tsukuba, Sociology) and Chieko Kurihara (National Institutes for Quantum and Radiological Science and Technology, Ethics), who participated as observers of the Expert Study Group-commented on the activities. Next, the five speakers held a panel discussion. In the panel discussion, questions from each speaker and participant were answered. In addition, there was growing interest in new coronavirus infections (COVID-19) that emerged as a new risk in the society [11]; therefore, the discussion was conducted in light of the Fukushima experience. Finally, the rapporteur summarized the session.

\section{Qualitative Analysis}

The participants' opinions were collected online. At the beginning of the panel session, the first author (Hiroko Yoshida) explained to the participants that they can comment on the Q\&A. The questions were summarized by the second author who specialized in qualitative studies and categorized the questions into general questions and subgroupspecific questions. To ensure the validity of the classification, a two-step process was adopted in which all authors provided consensus.

\section{Results and Discussion}

\section{Results and Discussion of Each Subgroup \\ 1) SG1 (leader, Takahiko Kono)}

The Fukushima accident was the first nuclear disaster to occur in the era of social networking services (SNS), and it 
had not only a radiation impact but also a secondary impact of an information disaster [12]. One reason for this is the lack of media literacy on the part of SNS information providers. Developing and applying criteria for information, content, and expression will help improve the literacy of information providers. Therefore, SG1 collected practices from several materials provided after the Fukushima accident and set criteria to evaluate them. The collection of data was limited to the websites of relevant ministries and agencies and research institutes immediately after the accident.

Four concepts were used in establishing the evaluation methods (criteria):

(1) The "Health on the Net (HON) code," an international code of conduct for health websites.

(2) "Health literacy," which includes information literacy in health and technology to communicate information to healthcare professionals $[10,13]$.

(3) "Suitability Assessment of Materials" (SAM), an index to measure the comprehensibility of materials [14].

(4) A consensus approach through a JHPS Q\&A website.

The evaluation items were classified into five categories: (1) content, (2) comprehensibility, (3) readability, (4) readers' cognitive and emotional aspects, and (5) consideration of ethical aspects.

To use these criteria, a two-stage policy was adopted in which documents were screened against the ethical aspects and then evaluated in the other four categories. A preliminary investigation was conducted in accordance with the above criteria and its procedures, and the validity of the criteria was verified (through comparison with previous studies on health information). Then, the materials that support good practice and what a radiation protection expert needs in order to explain radiation risks to the public were summarized.

\section{2) SG2 (leader, Wataru Naito)}

After the Fukushima accident, many practical activities related to public understanding of radiation risks (including research) were carried out in the disaster-stricken region [15-18]. By systematically organizing, analyzing, and discussing such activities in a cross-sectoral and systematic manner and making them informative and instructive, we can provide useful information for promoting public understanding of future radiation risks, preparing for future nuclear disasters, and supporting risk communication plans in the recovery phase. From this point of view, SG2 conducted a cross-sectional, systematic study and an analysis of practical activities on public understanding of radiation risks conducted after the accident, focusing on soft skills and communication tools.

Cases of practical activities for analysis and discussion were extracted from research papers, reports, websites, books, and other materials, or were based on discussions by SG2 members and the Expert Study Group, with a focus on the cases involved in communication between experts, local residents, and the local government. Each of the extracted cases was systematically summarized on an information arrangement sheet for analysis and discussion. In addition, recent and unique cases were analyzed and examined in detail. In all, 23 cases of practical activities were classified into six categories: (1) activities led by local residents, (2) meetings, seminars, and dialogues, (3) practical research activities by research institutions, (4) "citizen science" approaches, (5) unique communication methods, and (6) activities led by local government.

Following analysis and discussion, important factors identified were the placement of radiation risk in the daily context, communication using the decision-making system of the local community, the existence of persons who consistently carry out works and activities based on professional ethics and specialty, building trust through collaboration and dialogue, and utilizing a proven methodology. In addition, new approaches and issues for public understanding of radiation risks in the Internet age identified included the measurement of radiation dose by non-government organizations/non-profit organizations, publishing the results on websites and SNS, and interactive study meetings conducted in virtual spaces on SNS.

\section{3) SG3 (leader, Akihiro Sakoda)}

Since the Fukushima accident, radiation experts and research institutions have been working on the public understanding of radiation and risk. Although experts already recognized the importance of such activities, the experience after the accident highlighted the huge gap between ideal and reality in communication with the public $[19,20]$. Although individual lessons learned from the activities of experts at the individual and group levels have been reported, there is no overall review, so the collation and analysis of the objectives and approaches of various activities would be useful for considering the role of experts from the viewpoint of public understanding. 
We collected information on radiation and risk activities by experts before and after the Fukushima accident, and examined the impact of the accident on public understanding activities by experts and the important aspect of those activities. Because it is difficult to comprehensively collect information on the activities of experts at the individual and small group levels, we targeted academic societies as expert communities that are considered to be socially neutral. We selected six academic societies that study radiation and risk and had a history of public understanding activities before and after the accident (JHPS, Japanese Society of Radiation Safety Management, Atomic Energy Society of Japan, Japanese Radiation Research Society, Japanese Society of Radiological Technology, and Society for Risk Analysis, Japan). Information on public understanding activities was obtained from each society's website.

Before the accident, about half of the societies engaged in activities related to public understanding, but none of these activities was interactive. In the immediate aftermath of the accident, many societies conducted various interactive activities, such as public lectures, meetings, and online Q\&A sessions. Different societies adopted different media (meetings, Internet, etc.) and formats (dialogue, lectures, information dissemination, etc.), which we thought likely to create differences in the scale of application (individual, group, and mass), information quality and quantity, and accessibility. Most of the activities that started immediately after the accident ended after 3 to 5 years, but some societies still engage in grass-roots small-group dialogues. Some societies provided information through their websites as needed, but it seems that they have gradually returned to their pre-accident activities. Our examination of their activities after the accident identified the societies' philosophy, objective (operations), and relationship (tolerance) with their individual members as influential in the societies' public understanding activities.

\section{Comments from the Designated Speakers}

Dr. Igarashi specializes in sociology—urban/community sociology_not radiation or risk communication. He has played a central role in several projects referred to as "activities led by local residents" "'Safe and secure Kashiwa production for consumption" Round Table Conference, Iwaki Marine Corps "Umi Labo") from the standpoint of revitalizing regional agriculture and fisheries industries. He was also involved in the Expert Study Group as a communication ex- pert as well as sociologist. The overall goals of the Expert Study Group are to prepare for risks and to establish a relationship between academic societies' information transmission systems and local residents in normal times. The Expert Study Group:

(1) develops criteria for evaluating information dissemination through the Web by experts;

(2) classifies, evaluates, and extracts key elements of cases of communication practice;

(3) evaluates and summarizes communication activities of related academic societies.

The requirements for local/personal communication and mass communication are quite different. The former case requires many communicators and a high frequency of communication. In the latter case, however, too much information can contribute to confusion. From this point of view, for a prompt response in the former case, it is essential to establish two-way communication that contributes to building trust through cooperation with the decision-making system of the local community and key persons with high expertise among residents, as was reported in SG2. However, it would be difficult to form such a system with radiation-related academic societies nationwide, regardless of the localization of nuclear power plants although it could be possible in localized areas where nuclear power plants are sited. To respond to this situation, it is important to establish cooperation in normal times through networks established by local universities (especially local departments such as medical schools). On the other hand, in the latter case of mass communication, citizens pointed out that "There is too much information" and "The expert's messages are not consistent." This caused confusion immediately after the accident. SG3 reported that each academic society was independently disseminating information. This is understandable, but it is important to prepare a platform through which radiation-related academic societies can collaborate to disseminate information in an emergency. It is particularly important to note that when the leading issues of science are still being discussed by academic societies, the situation can be perceived by the general public as not being understood or revealed at all. It is necessary to disseminate information in consideration of this point. The most important thing to consider is not only the quality (the kind of content to be transmitted), but also the extent of reach (access) and effectiveness. This points to the need for an examination of why the voices of some non-mainstream experts were so pronounced. 
Dr. Kurihara was a member of the International Commission on Radiological Protection (ICRP) working group for the preparation of Publication 138, "Ethical foundation of the system of radiological protection" [21], she participated as an observer in the selection of criteria for evaluating information disseminated via the web in SG1 activities. The criteria are intended to allow senders to evaluate their own information. ICRP Publication 138 clarified four core ethical values, and I was delighted that the SG1 members were adapting them to use as a screening tool for evaluation. However, they must be expressed in concise terms as the "ethical values" or "ethical principles" of the ICRP. The ICRP Publication 138 clarifies that the ethical values that form the basis of the ICRP radiation protection system comprise four core ethical values (beneficence/non-maleficence, prudence, justice, and dignity) and three procedural ethical values (accountability, transparency, and stakeholder participation) which are linked to the practical implementation of the system of radiological protection. I describe these in concise terms as follows. (This is not the conclusion of SG1, however, but my interpretation.)

"Beneficence/non-maleficence" means promoting or doing good, avoiding causing harm. To evaluate information to send out, the sender should ask, "Is the risk-benefit balance optimal?" It is necessary to correctly and appropriately convey the risk of radiation, but at the same time also to ask whether avoiding the risk of radiation would result in loss of other benefits or other harm, and whether the balance is optimal. "Prudence" refers to the wisdom to make carefully considered decisions and to act in uncertain situations. The question is whether experts provide information and guidance for decision-making and action in uncertain situations. "Justice" refers to fairness in the distribution of advantages and disadvantages and in procedures; whether the information will lead to a greater disadvantage for those in a weaker position, while those in a stronger position will avoid disadvantage or will gain advantage. It asks whether stakeholders participate in making decisions and whether fair and equitable procedures are followed. "Dignity" means respecting the autonomy of individuals and communities (community groups) and their willingness to make their own decisions. It is a fundamental human right to receive respect for such intentions. Is the information we publish relevant to what individuals or communities want?

"Accountability" means that those involved in policy and action decisions are answerable to all those who are likely to be affected by their actions. "Transparency" refers to the disclosure of necessary information in an easy-to-understand manner without concealing inconvenient information and without making it hard to get the information. "Stakeholder participation" means involving all relevant parties in the decision-making process in a fair manner.

Finally, she reported two lessons from her colleagues in the ICRP working group and from the members of the Expert Study Group. Because "ethics" is a guide to what is right and what is not, risk communication without ethics tends to become "persuasion" and "self-justification explanation." And regardless of whether ethical values or principles are adopted in screening criteria or guiding principles, discussions of ethical values can help develop guiding principles and enhance sensitivity to needs.

\section{Panel Discussion}

The leaders of SG1, SG2, and SG3 expressed their opinions (Table 1) and comments on the remarks by doctors Igarashi and Kurihara as follows:

Kurihara introduced two ideas on ethics in regard to the question: "Not all individuals in a community have the same opinion or desire. If there is a conflict between the dignity of an individual and that of a community, are there specific guidelines on how to reconcile them?" First, we must not sacrifice the individual at any time, or do anything to make persons feel guilty; there should be no community preference. Second, we must value differences, accept differences as they are, communicate, discuss, and find common ground.

The discussion was based on the present social situation, when COVID-19 is spreading. At present, our daily life is greatly affected by the spread of COVID-19. What information does the public require in the context of the still high uncertainty, and how should experts respond? Members of the JHPS may learn from the spread of COVID-19 in the position of members of the public, not as experts, and observe how risk communication should operate in an emergency. Igarashi pointed out that the entire world is paying attention to the risks of COVID-19, and that it is possible to work together to summarize the opinions of experts and convey risks. It is necessary to establish a mechanism for communicating not only radiation risks but also other risks in normal times for both mass and regional (local) use. The results of the activities of the Expert Study Group should contribute to the creation of an information communication platform.

Finally, Kurihara suggested that the concept and system of 
Summary of the responses to the presentation

SG1, Kono: We would like to create specific criteria to screen information collected from websites from an ethical perspective. I would like to reflect Kurihara's comments here.

SG2, Naito: We recognize the difficulty and necessity of the approach to mass communications as explained by Dr. Igarashi. In particular, it is necessary to develop a mechanism that can effectively approach administrations and local government.

SG3, Sakoda: I mentioned the activities of the JRRS as an example of successful communication in the local community, but I have heard that there are difficulties in continuing the activities under normal circumstances in which there is relatively little interest or concern in radiation risk or in maintaining motivation of experts for activities. The continuation of such activities may depend on a strong sense of individual responsibility rather than on the organization of academic societies. In the case of mass communication, websites were the main source of information disseminated by the academic societies surveyed, and SNS was not used. It may be worth considering the use of SNS in the future. Since there is concern about the fact that understanding of the health effects of radiation was not well shared among experts, the JHPS and JRRS are working together to obtain consensus on radiation risks, initially from the scientific viewpoint.

Summary of opinions on COVID-19

SG1, Kono: In a situation where we are flooded with information on COVID-19, we would like to establish criteria that would enable the general public to make recommendations on what information is needed.

SG2, Naito: Unlike the Fukushima accident, it is difficult to distinguish the perpetrators from the victims in COVID-19, and there are differences in risk communication, such as the fact that incidents take place on a national scale. There are many experts in the field of platform creation, but they are not clearly identified. It would be nice to have a platform that can communicate risk information, and that does so while avoiding stigma or discrimination.

SG3, Sakoda: With COVID-19, risk communication is centered on doctors, so it may not be necessary for allied academic societies such as those dealing with infectious diseases to communicate risks themselves. In addition, academic societies and experts in basic viral systems rarely engage in risk communication. In the case of radiation, there are a variety of experts, from basic to applied, who communicate risks to the public. It would be a good idea for relevant academic societies and experts to exchange opinions. It is also necessary to document these and publish them. I hope that the Expert Study Group's activities will lead to such exchanges. There is a wide range of expert involvement in the current COVID-19 crisis, but people are listening to those who oversimplify or who echo their own beliefs. I feel that the way information is disseminated by experts is being asked here as well. It is important to increase opportunities for the JHPS to reach the general public during normal times so as to build an information communication platform.

JRRS, Japanese Radiation Research Society; SNS, social network service; JHPS, Japan Health Physics Society; COVID-19, coronavirus disease 2019.

radiation protection culture could be applied in the early stages of infection spread. However, the term "radiation protection culture" is poorly understood. Terms such as "social distance," "the new normal," and "catch corona" have entered everyday discourse. The radiation protection communicators can learn from COVID-19. For example, we can learn from COVID-19 that finding words that express a culture of radiation protection to protect the dignity of individuals, such as "to measure, to know, to think, and to dialogue to search for a common language" promoted by ETHOS in Fukushima, offers a means of preparing for a radiation disaster.

\section{Report from the Rapporteur}

This panel discussion provides an important point of view that should be reflected in future activities, as the top goals of the Expert Study Group and the way in which feedback is given to the field are taken up in the designated remarks. In addition, many comments on "actual responses of the residents" and "ethical aspect" were offered, so it is necessary to incorporate the viewpoints of not only the sender, but also the receiver in future. Moreover, information and ethics cannot be separated [22], and it is necessary to continue to examine ethical aspects. SG leaders 1 and 2 presented reports from researchers and practitioners in health physics and environmental risks who provided information after the Fukushima accident. In the designated discussion, experts in sociology and ethics discussed these issues from the perspective of their activities, specifically the overall goals for the activities of the three groups, local (personal) and mass communication, and ethical values. Many of the activities instituted by the experts after the accident were aimed at public understanding of science (that is, to provide knowledge to the residents), but by taking into account interactions with residents and their ethical norms, the experts shifted to supporting the residents' decision-making through public engagement. The need to consider content and channels is well known in the field of health communication [23], and overlaps with the above discussion.

The panel discussion explored the relationship between radiation risk and COVID-19 risk. The characteristics of the risks are different because the routes of transmission are different, although both are invisible threats that can be lifechanging. Following the nuclear disaster, creating social networks was effective in maintaining mental health, but COVID-19 disrupted those networks. The lessons from the nuclear disaster highlight the direct utility of knowledge and the 
Table 2. List of Questions and Comments from Participants in the Panel Session

Questions and comments
$\begin{aligned} & \text { Questions related to the overall activities } \\ & \text { of the Expert Study Group }\end{aligned}$
$\begin{aligned} & \text { Questions specific to each subgroup (SG) } \\ & \text { SG1 }\end{aligned}$
$\begin{array}{ll}\text { Are there any plans to examine the reactions of the residents, such as how much of the materials were actually } \\ \text { read, whether they were being used (such as how much they were accessed), and whether they were received } \\ \text { as intended? } \\ \text { How do you verify the "validity" mentioned in the summary? } \\ \text { Public distrust of government underlies the public's opposition to information disclosure and risk communication. } \\ \text { Will risk communication be easier to accept if the public is made aware of content that is apparently unrelated to } \\ \text { risk communication, such as the structure and ethics of the administration, as well as the respectfulness of the } \\ \text { explanation and the attitude of listening to the public? } \\ \text { Information collected only from the Internet is biased, so it may be necessary to interview members of the } \\ \text { academic societies. Looking back collected only from the academic activities that have been conducted so far, } \\ \text { do you think that they were sufficient? } \\ \text { If an academic society is regarded as an advocate of governmental policies, it will lose the trust of the public, as } \\ \text { the government is responsible for the Fukushima accident. Are there any examples of academic societies that } \\ \text { have shown consideration of this point? } \\ \text { Not all individuals in a community have the same opinions or desires. If there is a conflict between the dignity of } \\ \text { an individual and that of a community, are there specific guidelines on how to reconcile them? } \\ \text { In the case of the nuclear accident in Japan, it remains unclear whether the government or the operator was } \\ \text { responsible for the accident, exposure, and contamination. If the experts involved in the activities do not make it } \\ \text { clear that they are not representatives of either party, there may be major ethical problems. }\end{array}$
Others

need to apply it to new risks (adaptation).

How to implement risk communication in society was discussed in both the floor and designated discussions. It is also necessary to develop relationships with local residents in normal times, to establish an information transmission system that functions effectively, and to establish cooperation between local communities and organizations that are already trusted. Although it is difficult for the Expert Study Group to undertake all of these activities quickly, the JHPS and academic societies can advance activities that will ultimately benefit residents' lives.

\section{Results of the Qualitative Analysis of Participants' Comments}

There were nine comments from the participants, two of which were general questions, and the others were comments for subgroups (Table 2). The overall question concerned the interaction of the three subgroups in the Expert Study Group and the feedback of the results obtained. Feedback on the results obtained is a very important topic after the Fukushima accident. Kobayashi et al. [24] stated that the participants should also be able to gain benefits from the survey. Although the results of this study do not necessarily provide feedback to residents, we believe that providing feedback to relevant experts will lead to better communication with residents and improve their wellbeing [25]. Individ- ual questions to subgroups included methods to improve the objectivity of results, comments on "Trust” of key concepts of communication [26], and comments on ethics. To improve the objectivity of the survey, it is necessary to accumulate more data, and since there is a high level of interest in ethics among relevant researchers, it is necessary to have opportunities to further increase knowledge at the academic societies in the future.

\section{Conclusion}

Many participants are interested in the public understanding of science and radiation risk. The Fukushima accident shows that accurate and easy-to-understand information from experts is required. We thank the many participants of this panel session. The Expert Study Group is currently summarizing the results of its activities for publication as a research paper. We will include comments from Igarashi and Kurihara, the contents of the panel discussion, and questions and comments from participants. Although the Expert Study Group's activities have been completed, as specialists in radiation protection and as members of the JHPS, we will continue our discussions on how to communicate radiation risks to the general public. 


\section{Conflict of Interest}

No potential conflict of interest relevant to this article was reported.

\section{Acknowledgements}

This paper, which was already published in Japanese Journal of Health Physics, an academic journal of the Japan Health Physics Society, was translated with permission of Japanese Journal of Health Physics and added an explanation for international readers. This work was supported by the Program of the Network-type Joint Usage/Research Center for Radiation Disaster Medical Science.

\section{Author Contribution}

Conceptualization: Yoshida H, Kuroda Y. Data curation: Kuroda Y. Formal analysis: Kuroda Y. Project administration: Kuroda Y. Writing - original draft: Yoshida H, Kuroda Y, Kono T, Naito W, Sakoda A. Writing - review \& editing: Yoshida H, Kuroda Y. Investigation: Yoshida H, Kuroda Y. Resources: Kuroda Y, Kono T, Naito W, Sakoda A. Supervision: Yoshida H.

\section{References}

1. Murakami M, Sato A, Matsui S, Goto A, Kumagai A, Tsubokura $\mathrm{M}$, et al. Communicating with residents about risks following the Fukushima nuclear accident. Asia Pac J Public Health. 2017; 29(2_suppl):74S-89S.

2. Perko T. Risk communication in the case of the Fukushima accident: Impact of communication and lessons to be learned. Integr Environ Assess Manag. 2016;12:683-686.

3. Shimura T, Yamaguchi I, Terada H, Robert Svendsen E, Kunugita N. Public health activities for mitigation of radiation exposures and risk communication challenges after the Fukushima nuclear accident. J Radiat Res. 2015;56:422-429.

4. Takamura N, Taira Y, Yoshida K, Nakashima-Hashiguchi K, Orita M, Yamashita S. Communicating radiation risk to the population of Fukushima. Radiat Prot Dosimetry. 2016;171:23-26.

5. Sato A, Honda K, Ono K, Kanda R, Hayashi TI, Takeda Y, et al. Reviews on common objectives and evaluation indicators for risk communication activities from 2011 to 2017. PeerJ. 2020; 8:e9730.

6. Naito W, Uesaka M, Kuroda Y, Kono T, Sakoda A, Yoshida H. Examples of practical activities related to public understanding of radiation risk following the Fukushima nuclear accident. Radioprotection. 2020;55:297-307.
7. Kuroda Y, Koyama Y, Yoshida H, Naito W. Preparation of an" information booklet for returnees"-Building trust through collaboration with local communities. Radioprotection. 2020;55:309315.

8. Lazo T. Involving stakeholders in radiological protection decision making: recovery history and lessons from the people of Fukushima. Ann ICRP. 2016;45(2_suppl):105-109.

9. Lochard J, Ando R, Takagi H, Endo S, Momma M, Miyazaki M, et al. The post-nuclear accident co-expertise experience of the Suetsugi community in Fukushima Prefecture. Radioprotection. 2020;55:225-235.

10. Goto A, Rudd RE, Lai AY, Yoshida K, Suzuki Y, Halstead DD, et al. Leveraging public health nurses for disaster risk communication in Fukushima City: a qualitative analysis of nurses' written records of parenting counseling and peer discussions. BMC Health Serv Res. 2014;14:129.

11. Muto K, Yamamoto I, Nagasu M, Tanaka M, Wada K. Japanese citizens' behavioral changes and preparedness against COVID-19: an online survey during the early phase of the pandemic. PLoS One. 2020;15:e0234292.

12. Yamashita S. Fukushima nuclear power plant accident and comprehensive health risk management-global radiocontamination and information disaster. Trop Med Health. 2014;42(2 Suppl):S93-S107.

13. Ishikawa H, Nomura K, Sato M, Yano E. Developing a measure of communicative and critical health literacy: a pilot study of Japanese office workers. Health Promot Int. 2008;23:269-274.

14. Hoffmann T, Ladner Y. Assessing the suitability of written stroke materials: an evaluation of the interrater reliability of the suitability assessment of materials (SAM) checklist. Top Stroke Rehabil. 2012;19:417-422.

15. Brown A, Franken P, Bonner S, Dolezal N, Moross J. Safecast: successful citizen-science for radiation measurement and communication after Fukushima. J Radiol Prot. 2016;36:S82-S101.

16. Naito W, Uesaka M, Yamada C, Kurosawa T, Yasutaka T, Ishii H. Relationship between individual external doses, ambient dose rates and individuals' activity-patterns in affected areas in Fukushima following the Fukushima Daiichi Nuclear Power Plant Accident. PLoS One. 2016;11:e0158879.

17. Yoshida-Ohuchi H, Kanagami T, Satoh Y, Hosoda M, Naitoh Y, Kameyama M. Indoor radiocaesium contamination in residential houses within evacuation areas after the Fukushima nuclear accident. Sci Rep. 2016;6:26412.

18. Yasutaka T, Kanai Y, Kurihara M, Kobayashi T, Kondoh A, Takahashi T, et al. Dialogue, radiation measurements and other collaborative practices by experts and residents in the former evacuation areas of Fukushima: a case study in Yamakiya District, Kawamata Town star. Radioprotection. 2020;55:215-224.

19. Ohtsuru A, Tanigawa K, Kumagai A, Niwa O, Takamura N, Midorikawa S, et al. Nuclear disasters and health: lessons learned, 
challenges, and proposals. Lancet. 2015;386:489-497.

20. Fujigaki Y. Lessons from Fukushima for Responsible Innovation: How to Construct a New Relationship Between Science and Society? In: Lechevalier S, editors. Innovation beyond technology. Singapore: Springer; 2019. p. 223-239.

21. Cho KW. Ethical foundations of the radiological protection system. Ann ICRP. 2016;45(1_suppl):297-308.

22. Cohen E, Cornwell L. A question of ethics: developing information system ethics. J Bus Ethics. 1989;8:431-437.

23. Nutbeam D. Health literacy as a public health goal: a challenge for contemporary health education and communication strate- gies into the 21st century. Health Promot Int. 2000;15:259-267.

24. Kobayashi T, Takebayashi Y, Murakami M. Disaster-zone research: participants should benefit too. Nature. 2020;579:193.

25. Maitre M, Crouail P, Schneider T, Kuroda Y, Miyazaki M, Tanigawa $\mathrm{K}$, et al. Living conditions and health status of populations living in territories impacted by nuclear accidents: some lessons for developing health surveillance programme. Environ Int. 2021;147:106294.

26. Covello VT. Risk communication, radiation, and radiological emergencies: strategies, tools, and techniques. Health Phys. 2011;101:511-530. 